\title{
Lixisenatide Improves Glycemic Control in Asian Type 2 Diabetic Patients Inadequately Controlled With Oral Antidiabetic Drugs: An Individual Patient Data Meta-Analysis
}

Hua Shu $\cdot$ Li-na Gu $\cdot$ Li-chuang Men · Ju-ming Lu

Received: September 8, 2016 / Published online: October 31, 2016

(C) The Author(s) 2016. This article is published with open access at Springerlink.com

\begin{abstract}
Introduction: Lixisenatide is a novel GLP-1 receptor agonist for the treatment of type 2 diabetes mellitus (T2DM). Its efficacy and safety have been assessed in a series of phase 3 studies included in the GetGoal program. In these studies, lixisenatide was found to be superior to placebo in glycemic control. The aim of this meta-analysis was to assess the safety and efficacy of lixisenatide as an adjunct therapy in Asian patients with T2DM in adequately controlled with oral antidiabetic drugs (OADs).
\end{abstract}

Enhanced content To view enhanced content for this article go to http://www.medengine.com/Redeem/ 2017F0602F399121.

Electronic supplementary material The online version of this article (doi:10.1007/s13300-016-0207-6) contains supplementary material, which is available to authorized users.

H. Shu $\cdot$ J. Lu $(\bowtie)$

Department of Endocrinology, Chinese PLA General Hospital, No. 28 Fuxing Road, Haidian District, Beijing, China

e-mail: 13911682036@126.com

L. Gu $\cdot$ L. Men

Sanofi (China) Investment Co., Ltd., 19F Tower III Kerry Center, 1228 Middle Yan'an Road, Shanghai, China
Methods: We performed a meta-analysis from five lixisenatide phase 3 studies. In each of these multiethnic studies, patients with T2DM inadequately controlled (glycated hemoglobin, HbA1c $\geq 7 \%$ ) with established OADs were randomized to lixisenatide or placebo for 24 weeks, with a balanced distribution of Asian patients in these two arms (503 and 338 patients in the intent-to-treat population, respectively).

Results: Lixisenatide was superior to placebo in reducing HbA1c (weighted, total mean difference $-0.57 \% ; P=0.002$ ). More patients treated with lixisenatide versus placebo achieved $\mathrm{HbA1c}$ targets of $\leq 7 \%(49.1 \%$ vs. $28.4 \%, P=0.003)$. Lixisenatide was superior to placebo in lowering 2-h postprandial glucose (PPG) (weighted, total mean difference $-5.50 \mathrm{mmol} / \mathrm{l}, \quad P=0.0005)$. More patients treated with lixisenatide versus placebo achieved 2-h PPG targets of $\leq 7.8 \mathrm{mmol} / \mathrm{l}$ (39.2\% vs. $2.2 \%, P<0.0001)$. More patients treated with lixisenatide versus placebo achieved both an HbA1c target of $\leq 7 \%$ and a 2-h PPG target of $\leq 10 \mathrm{mmol} / \mathrm{l}$ (34.8\% vs. 2.69\%, $P<0.00001)$. The body weight of the lixisenatide group tended to decrease. Lixisenatide was generally well tolerated. 
Conclusion: Lixisenatide as an adjunct therapy can significantly improve the glycemic control of Asian patients with type $2 \mathrm{DM}$ who do not meet targets for glycemic control with an established OAD regimen.

Funding: Sanofi (China) Investment Co., Ltd., Shanghai, China.

Keywords: Asia; GLP-1 receptor agonist; Glycemic control; Lixisenatide; Postprandial glucose; Type 2 diabetes mellitus

\section{INTRODUCTION}

Globally, effective strategies for the clinical management of type 2 diabetes mellitus (T2DM) are receiving urgent attention as the world's T2DM population is nearly 400 million. In Asia, the unprecedented rise in the prevalence of $\mathrm{T} 2 \mathrm{DM}$ is particularly alarming. For instance, in China, the prevalence of T2DM increased from 3.2\% in 1996 to ca. 9.7\% in 2013, with the Chinese T2DM population at nearly 100 million, which represents approximately a quarter of the world's diabetic population $[1,2]$.

Currently there is genuine concern about the extent of poor glycemic control in a large portion of the Asian T2DM population; for instance, recent evidence has shown that approximately two-thirds of patients in China who are treated with oral antidiabetic drugs (OADs) do not achieve the glycated hemoglobin (HbA1c) targets of $\leq 6.5$ or $\leq 7 \%$ [3-5].

Patients from East Asia with T2DM share common pathophysiologic characteristics, which are distinct from those of their European counterparts. In East Asian countries diabetes occurs at a much lower BMI than elsewhere in the world [6], and the majority of East Asians with prediabetes have impaired glucose tolerance as opposed to impaired fasting glucose [7]. Another feature characterizing T2DM in Asian populations is the tendency to develop young-onset diabetes. Studies conducted in different East Asian populations have found a mean age of diagnosis of T2DM typically around 50 years [8]. Impaired beta cell function plays an important role in the pathogenesis of diabetes in Asians, especially in those who are not overweight or have a positive family history. Importantly, HbA1c values seem to be higher among Asians than Europeans, which is likely related to genetic similarities [9]. In addition to shared genetic and pathophysiological characteristics, East Asians have similar dietary habits. Therefore, a common treatment strategy for this population is indicated.

Currently in East Asia, patients with T2DM are commonly prescribed metformin/sulfonylurea, and the initiation of insulin therapy is often delayed [4, 5]. Because inadequately controlled T2DM can give rise to serious, irreversible medical complications, there is thus an urgent need to identify alternative treatment strategies that would improve glycemic control in the East Asian T2DM population.

Glucagon-like peptide-1 (GLP-1) receptor agonists increase insulin release, suppress glucagon secretion, and delay gastric emptying, which has been shown to be an effective strategy for improving glucose control in T2DM [10]. Furthermore, GLP-1 agonists are associated with a reduction in HbA1c levels, a low incidence of hypoglycemia, and a reduction in body weight [10]. GLP-1 receptor agonists are generally well tolerated, and side effects are mainly limited to mild gastrointestinal disturbances in a relatively small proportion of patients. 
Lixisenatide is a novel, once-daily prandial GLP-1 receptor agonist for the treatment of T2DM [11-16]. Its efficacy has been assessed across the full spectrum of the natural history of T2DM in a series of lixisenatide phase 3 studies that were included in the GetGoal study programme. The GetGoal clinical study programme assessed glycemic control and safety following lixisenatide treatment in T2DM patients with uncontrolled glycemia despite diet and exercise interventions, single OADs, combinations of two or more OADs, or basal insulin. In the GetGoal studies, lixisenatide was found to be superior to placebo in reducing $\mathrm{HbA1c}$ and postprandial glucose (PPG) levels with a low incidence of hypoglycemia. Accordingly, lixisenatide was granted market authorization by the European Medicines Agency in 2013.

In the GetGoal study programme, one study enrolled only Asian patients who were inadequately controlled by OADs, and an additional four GetGoal randomized controlled trials (RCTs) included Asian patients in cohorts of mixed ethnicity. The primary objective of this meta-analysis was to amalgamate the safety and efficacy data of the Asian T2DM patients enrolled in those five RCTs, so as to broaden the database concerning the safety and efficacy of lixisenatide in Asian patients with T2DM who do not achieve adequate glycemic control with an established OAD regimen.

\section{METHODS}

\section{Data Sources}

To identify relevant clinical studies, we performed a manual search on ClinicalTrials.gov. Firstly, we searched for lixisenatide phase 3 studies from the GetGoal programme. The terms used in the search were "phase 3", "lixisenatide", and "GetGoal" and a total of 13 studies were identified. Secondly, we also searched on ClinicalTrials.gov and pubmed.gov to make sure study primary results had been published previously. Thirdly, we further narrowed down to studies which had enrolled Asian patients and evaluated lixisenatide as an add-on treatment to OADs and compared with placebo. The terms used in this search were "Asian" and "OAD" and "placebo controlled". Five studies were identified after this three-step search.

\section{Analysis Design}

The five randomized, placebo-controlled phase 3 studies of lixisenatide (GetGoal-M, GetGoal-F1, GetGoal-S, GetGoal-P, GetGoal-M-Asia) belonged to the GetGoal study programme, which was a series of 11 multinational RCTs that investigated the efficacy and safety profile of lixisenatide $20 \mu \mathrm{g}$ once daily across the spectrum of patients with T2DM. All five of the RCTs included in the present meta-analysis enrolled, amongst others, Asian patients with T2DM who had inadequate glycemic control (HbA1c $\geq 7 \%)$ despite an established regimen of OADs. All patients received either lixisenatide or placebo as an adjunct to an established OAD regimen. Patients self-administered the study drug according to the regimens of the individual trials. The designs of each of the RCTs have been reported previously (see Table 1 for information on the individual studies). Briefly, GetGoal-M (NCT01169779) assessed the efficacy and safety of lixisenatide as an adjunct to metformin in patients with T2DM not adequately controlled with metformin. 
Table 1 Individual study information

\begin{tabular}{|c|c|c|c|c|c|c|}
\hline \multirow[t]{2}{*}{$\begin{array}{l}\text { Study code } \\
\text { Short name }\end{array}$} & \multirow[t]{2}{*}{ Duration of treatment } & \multirow[t]{2}{*}{$\begin{array}{l}\text { Test drug and } \\
\text { treatment regimen }\end{array}$} & \multirow{2}{*}{$\begin{array}{l}\text { Overall } \\
\text { patient } \\
\text { number } \\
(\text { ITT) } \\
N\end{array}$} & \multicolumn{3}{|c|}{$\begin{array}{l}\text { Number of Asian patients } \\
\text { analyzed for primary } \\
\text { endpoint (HbA1c) (ITT) }\end{array}$} \\
\hline & & & & $\begin{array}{l}\text { Lixisenatide } \\
n\end{array}$ & $\begin{array}{l}\text { Placebo } \\
n\end{array}$ & $\begin{array}{l}\text { All } \\
N\end{array}$ \\
\hline $\begin{array}{l}\text { EFC6014 } \\
\text { GetGoal-F1 }\end{array}$ & $\begin{array}{l}24 \text { weeks followed by a } \\
\geq 52 \text {-week double-blind } \\
\text { extension }\end{array}$ & $\begin{array}{l}\text { OAD + lixisenatide } \\
10-20 \mu \mathrm{g} \text { (one-step), } \\
\text { qd; or } \\
\text { OAD + lixisenatide } \\
10-15-20 \mu \mathrm{g} \\
\text { (two-step), qd; or } \\
\text { OAD + placebo } \\
\text { (one-step), qd; or } \\
\text { OAD + placebo } \\
\text { (two-step), qd }\end{array}$ & 479 & 14 & 7 & 21 \\
\hline $\begin{array}{l}\text { EFC10743 } \\
\text { GetGoal-P }\end{array}$ & & $\begin{array}{l}\text { OAD + lixisenatide } \\
20 \mu \mathrm{g} \text {, qd; or } \\
\text { OAD + placebo qd }\end{array}$ & 484 & 22 & 9 & 31 \\
\hline $\begin{array}{l}\text { EFC6017 } \\
\text { GetGoal-G-M }\end{array}$ & & $\begin{array}{l}\text { OAD + lixisenatide } \\
20 \mu \mathrm{g} \text {, qd (morning) } \\
\text { qd; or } \\
\text { OAD + lixisenatide } \\
20 \mu \mathrm{g} \text {, qd (evening) } \\
\text { qd; or } \\
\text { OAD + placebo, qd } \\
\text { (morning) or } \\
\text { OAD + placebo, qd } \\
\text { (evening) }\end{array}$ & 680 & 40 & 11 & 51 \\
\hline $\begin{array}{l}\text { EFC6015 } \\
\text { GetGoal-S }\end{array}$ & & $\begin{array}{l}\text { OAD + lixisenatide } \\
20 \mu \mathrm{g} \text {, qd; or } \\
\text { OAD + placebo qd }\end{array}$ & 856 & 242 & 123 & 365 \\
\hline $\begin{array}{l}\text { EFC11321 } \\
\text { GetGoal-G-M-Asia }\end{array}$ & 24 weeks & $\begin{array}{l}\text { OAD + lixisenatide } \\
20 \mu \mathrm{g} \text {, qd; or } \\
\text { OAD + placebo qd }\end{array}$ & 388 & 185 & 188 & 373 \\
\hline Overall & & & 2887 & 503 & 338 & 841 \\
\hline
\end{tabular}

ITT intent-to-treat 
GetGoal-F1 (NCT00713830) assessed the efficacy and safety of four treatment schedules with lixisenatide-a one-step or two-step dose escalation, lixisenatide once daily for 12 weeks as a one-step dose increase ( $10 \mu \mathrm{g}$ for 2 weeks, then $20 \mu \mathrm{g}$ ) or two-step dose increase (10 $\mu \mathrm{g}$ for 1 week, $15 \mu \mathrm{g}$ for 1 week, then $20 \mu \mathrm{g}$ )—as an adjunct to metformin in patients with T2DM not adequately controlled with metformin. GetGoal-P (NCT00763815) assessed the efficacy and safety of lixisenatide as an adjunct to pioglitazone in patients with T2DM not adequately controlled with pioglitazone. GetGoal-S (NCT00713830) assessed the efficacy and safety of lixisenatide as an adjunct to sulfonylurea in patients with T2DM not adequately controlled with sulfonylurea, and GetGoal-M-Asia (NCT01169779) assessed the efficacy and safety of lixisenatide in Asian patients with T2DM inadequately controlled by metformin (with or without sulfonylurea).

For the meta-analysis, the data on Asian patients included in the five GetGoal studies were extracted, amalgamated, and analyzed according to the protocol of the meta-analysis. The GetGoal programme was a series of phase 3, randomized, placebo-controlled trials conducted at centers across the globe. All studies were sponsored by Sanofi.

\section{Inclusion Criteria}

Only GetGoal studies that included Asian adults (men and women) with a confirmed diagnosis of T2DM (as defined by the World Health Organization, WHO) at least 1 year prior to study entry were eligible for inclusion in the meta-analysis. All patients had inadequate glycemic control (HbA1c levels $\geq 7 \%$ ) despite an established regimen of OADs and were in the intent-to-treat populations. In all of the included studies, patients were randomly assigned to either lixisenatide or placebo as an adjunct to their usual $\mathrm{OAD}(\mathrm{s})$, and they self-administered the study drug. The OADs that were allowed in the studies included in this meta-analysis were either metformin (1.0-1.5 mg/day) \pm sulfonylurea (at least half of the maximum recommended dose as per the package insert) or pioglitazone (at least $30 \mathrm{mg} /$ day).

\section{Endpoints}

The primary endpoint of this meta-analysis (and of the five GetGoal trials) was the mean change in HbA1c from baseline to week 24 .

Secondary endpoints included the number of patients who achieved HbA1c target levels of $\leq 7 \%$ at week 24; the mean change in 2-h PPG values after a standardized meal test from baseline to week 24; the number of patients who achieved a PPG of $\leq 7.8 \mathrm{mmol} / \mathrm{l}$ at week 24; the number of patients who achieved an HbA1c target of $\leq 7 \%$ as well as a 2-h PPG of 10 $\mathrm{mmol} / \mathrm{l}$ at week 24 ; the mean change in fasting plasma glucose (FPG); the mean change in body weight from baseline to week 24; and the number (\%) of patients who experienced treatment-emergent adverse events (TEAEs) or serious TEAEs.

The data items extracted from each of the selected studies are listed in Table 2, and the main findings of the individual studies included in the meta-analysis with regard to HbA1c (percentage reduction), number of patients who achieved HbA1c targets of $\leq 6.5 \%$ or $\leq 7 \%$, 2-h PPG, and safety are listed in Tables S1-4 in the supplementary material.

\section{Statistical Methods}

All meta-analyses were performed using RevMan, version 5.3 (Cochrane Collaboration, 
Table 2 Data items extracted from selected studies

\begin{tabular}{|c|c|}
\hline \multirow[t]{5}{*}{ Demographics } & Age \\
\hline & Gender \\
\hline & Body weight and body mass index \\
\hline & HbAlc at study entry (baseline) \\
\hline & FPG at study entry (baseline) \\
\hline \multirow{7}{*}{$\begin{array}{l}\text { Efficacy } \\
\text { parameters }\end{array}$} & Change in HbAlc \% from baseline (week 1) to end of treatment (week 24) \\
\hline & Number (\%) of patients who achieved an HbAlc target of $\leq 7 \%$ at week 24 \\
\hline & $\begin{array}{l}\text { Change in 2-h PPG after a standardized meal administered at baseline and at the end of treatment } \\
\text { (week 24) }\end{array}$ \\
\hline & Number $(\%)$ of patients who achieved PPG $\leq 7.8 \mathrm{mmol} / \mathrm{l}$ at week 24 \\
\hline & Change in FPG from baseline (week 1) to end of treatment (week 24) \\
\hline & Number $(\%)$ of patients who achieved FPG of $\leq 6.1$ and $\leq 7.0 \mathrm{mmol} / 1$ \\
\hline & Change in body weight from baseline (week 1) to end of treatment (week 24) \\
\hline Safety parameters & Number $(\%)$ of patients with TEAEs and serious TEAEs \\
\hline
\end{tabular}

$H b A 1 c$ glycated hemoglobin, FPG fasting plasma glucose, $P P G$ postprandial glucose

Copenhagen). RevMan 5.3 was also used to generate forest plots.

The following analysis populations were identified: (1) the HbA1c population, which included data from all randomized patients who had at least one dose of the study drug (lixisenatide or placebo) and one baseline and one post-baseline HbA1c result; (2) the 2-h PPG population, which included data from all randomized patients who had at least one dose of the investigational medicinal product (IMP) and one baseline and one post-baseline PPG result; (3) the FPG population, which included data from all randomized patients who had at least one dose of IMP and one baseline and one post-baseline FPG result; (4) the body weight analysis population, which included all randomized patients who had at least one dose of IMP and at least one baseline and one post-baseline body weight measurement; and (5) the safety population, which included all randomized patients who had at least one dose of study medication.

Descriptive statistics were used to measure and describe the clinical characteristics and patient demographic data, as well as to measure and describe the efficacy and safety outcomes. The number of patients and the associated percentage of the total number of patients with the relevant data reported were determined for dichotomous variables. The count, mean \pm standard deviation (SD), and median were reported for continuous variables. Treatment arms within each group were compared with one another, with $P$ values calculated using a Chi square $\left(\chi^{2}\right)$ test or analysis of variance test where appropriate.

Standard meta-analytic techniques were applied to assess the overall outcome measures using a random-effects model with an inverse variance method to determine weighted mean differences with 95\% confidence intervals (CIs) 
for continuous variables and Mantel-Haenszel odds ratios for all dichotomous outcome data. A $P$ value of 0.05 was used to determine the level of statistical significance.

Quantification of heterogeneity was examined with $I^{2}$ to measure the degree of total variation across trials owing to heterogeneity and establish the consistency of evidence. $I^{2}$ values greater than 50\% indicate a substantial level of heterogeneity; if heterogeneity was observed, this was accommodated using a random-effects model.

\section{Compliance with Ethics Guidelines}

All procedures in the trials included in this current meta-analysis were in accordance with the responsible committee on human experimentation (institutional and national) and with the Helsinki Declaration of 1964, as revised in 2013. Informed consent was obtained from all patients for being included in the studies. This meta-analysis is based on previously conducted studies, and does not involve any new studies of human or animal subjects performed by any of the authors.

\section{RESULTS}

In total, 883 Asian patients with T2DM were available from the five GetGoal studies for inclusion in the meta-analysis. All of the patients had inadequate glycemic control (HbA1c levels $\geq 7 \%$ ) on an established regimen of OADs (metformin \pm sulfonylurea or pioglitazone). Of the 883 patients, 536 were assigned to lixisenatide and 347 to placebo as an adjunct to the patients' established OAD regimen. The demographics of the analysis populations for the meta-analysis are reported in Table 3. The mean (SD) value of age, BMI, weight, HbA1c, and FPG at baseline, and the percentages of male patients were well balanced between two treatment groups.

\section{HbA1c \%}

Compared with placebo, lixisenatide $20 \mu$ g once daily as an adjunct to an established OAD regimen significantly reduced $\mathrm{HbA} 1 \mathrm{c}$ from baseline to week 24 in patients with inadequate glycemic control (weighted, total mean difference $-0.57 \% ; P=0.002$; Table 4 ). The potential heterogeneity of the primary endpoint was high $\left(I^{2}=79 \%\right)$, but this was accommodated by the randomized-effects model.

\section{Number (\%) of Patients Achieving HbA1c Targets of $\leq 7 \%$}

Significantly more patients in the lixisenatide versus the placebo treatment group achieved the HbA1c targets of $\leq 7 \%(49.1 \%$ vs. $28.4 \%$, $P=0.003$ ) (Table 5). The odds ratios (ORs) for HbA1c $\leq 7 \%$ were $0.18 \quad(0.06,0.57$, random-effects model).

\section{Two-hour PPG}

Two-hour PPG was measured in three of the five GetGoal studies only (GetGoal-M-Asia, GetGoal-M, and GetGoal-S). Overall, lixisenatide was superior to placebo in lowering 2-h PPG at the end of the 24-week treatment period (weighted, total mean difference $-5.50 \mathrm{mmol} / \mathrm{l}, P=0.0005)$. Table 6 shows the change in 2-h PPG for lixisenatide versus placebo for all the treatment groups. The potential heterogeneity for the primary endpoint was relatively high $\left(I^{2}=89 \%\right)$, but this was accommodated using a random-effects model. 


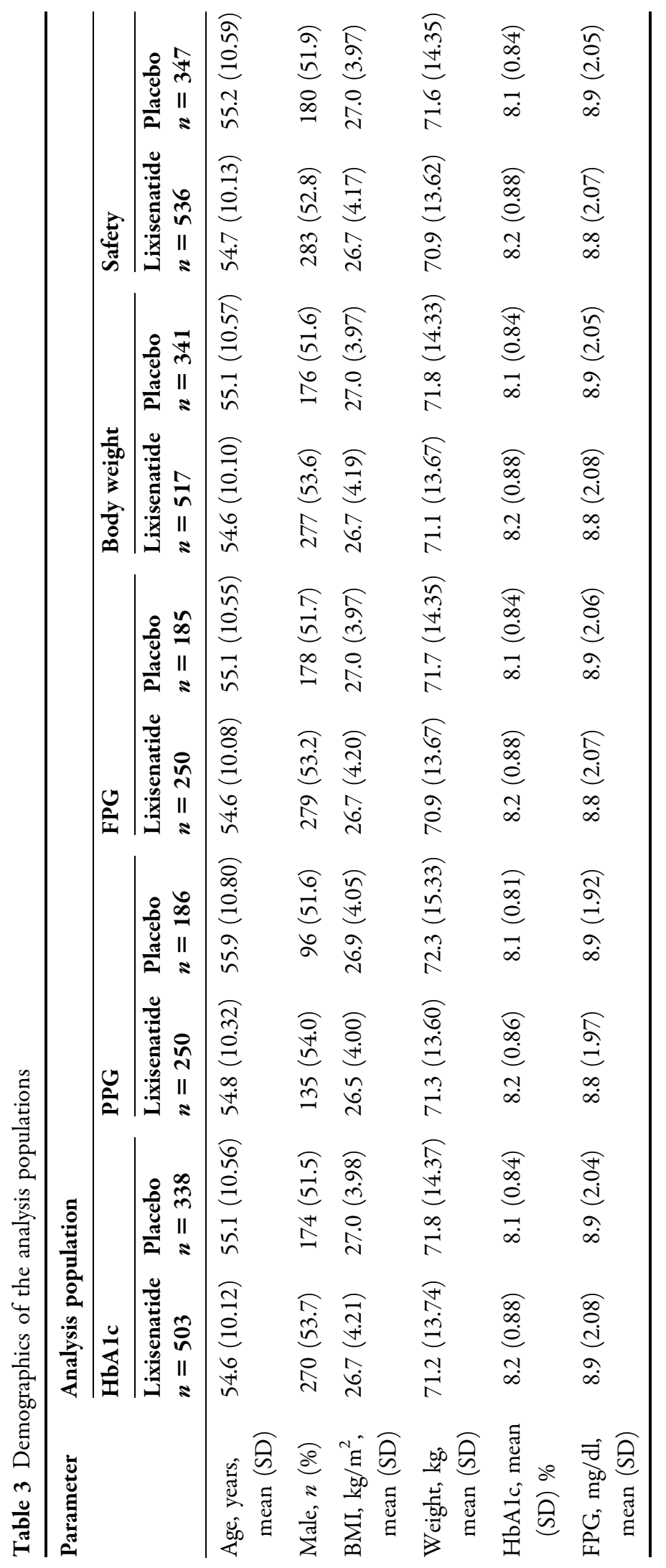




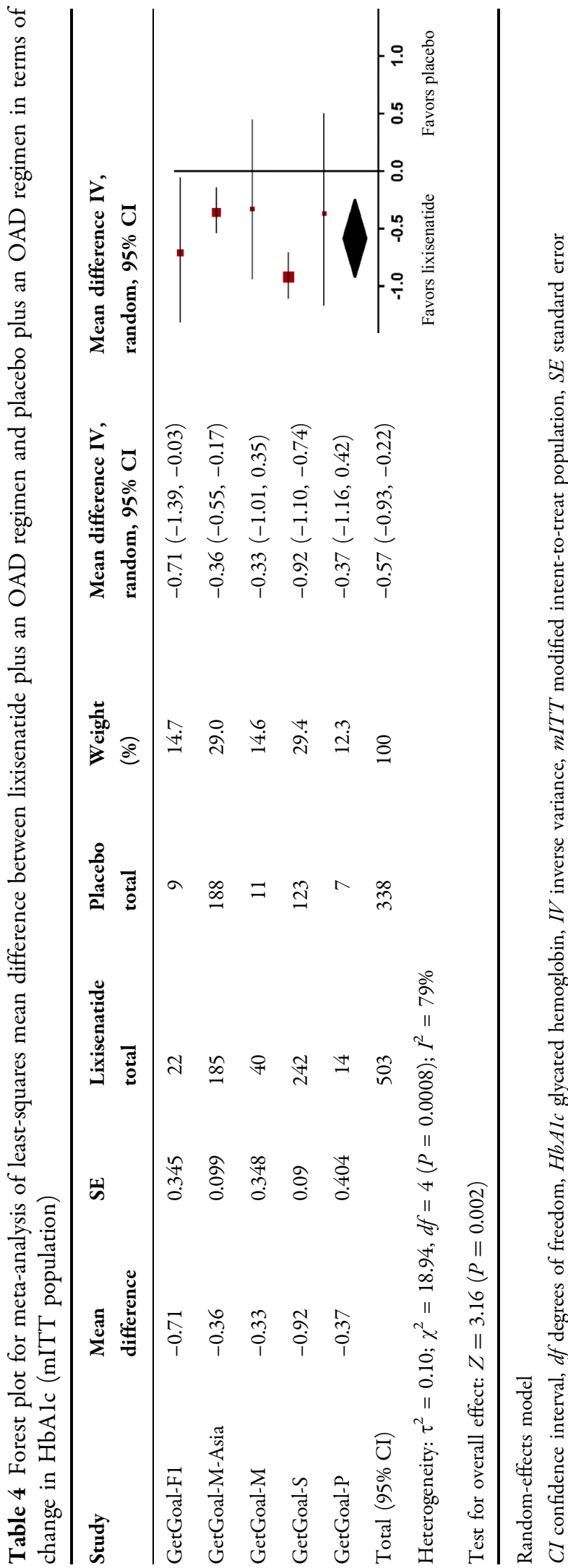

\section{Number (\%) of Patients Achieving 2-h PPG Targets of $\leq 7.8$}

Significantly more patients treated with lixisenatide versus placebo achieved 2-h PPG targets of $\leq 7.8(39.2 \%$ vs. $2.2 \%, P<0.0001)$. The OR for achieving a target of $\leq 7.8 \mathrm{mmol} / \mathrm{l}$ was 0.06 (95\% CI 0.01, 0.22), at the end of the 24-week treatment period (random-effects model; see Table 7).

\section{Number (\%) of Patients Achieving} an HbA1c Target of $\leq 7 \%$ and a $2-\mathrm{h}$ PPG Target of $\leq 10 \mathrm{mmol} / \mathrm{l}$

Significantly more patients treated with lixisenatide versus placebo achieved both an HbA1c target of $\leq 7 \%$ as well as a 2 -h PPG target of $\leq 10 \mathrm{mmol} / \mathrm{l} \quad(34.8 \%$ vs. $2.69 \%$, respectively, $\quad P<0.00001)$. The $\mathrm{OR}$ for achieving this composite endpoint was 0.07 $(95 \%$ CI $0.03,0.18)$ at the end of the 24 -week treatment period (random-effects model; see Table 8).

FPG

Lixisenatide was superior to placebo in lowering FPG $(P<0.0001)$. The mean difference in FPG between the lixisenatide and placebo groups at the end of the 24-week treatment period was $-0.51 \mathrm{mmol} / \mathrm{l} \quad(-0.76,-0.26$; random-effects model).

\section{Change in Body Weight}

Patients treated with lixisenatide generally had a stable body weight with a trend towards a decrease in body weight at the end of the 24-week treatment period [mean difference between groups $-0.29 \mathrm{~kg}(-0.60,0.01)$, both fixed and random-effects models]. 
Table 5 Forest plots for lixisenatide versus placebo in terms of percentage of patients with HbAlc values $\leq 7 \%$

\begin{tabular}{|c|c|c|c|c|c|c|c|c|c|}
\hline \multirow[t]{2}{*}{ Study } & \multicolumn{2}{|c|}{ Lixisenatide } & \multicolumn{2}{|c|}{ Placebo } & \multirow{2}{*}{$\begin{array}{l}\text { Weight } \\
\text { (\%) }\end{array}$} & \multirow{2}{*}{$\begin{array}{l}\text { Odds ratio } \\
\text { M-H, } 95 \% \text { CI }\end{array}$} & \multirow{2}{*}{\multicolumn{2}{|c|}{$\begin{array}{l}\text { Odds ratio } \mathrm{M}-\mathrm{H} \text {, } \\
\text { random, } 95 \% \mathrm{CI}\end{array}$}} & \\
\hline & Events & Total & Events & Total & & & & & \\
\hline GetGoal-F1 & 11 & 22 & 1 & 9 & 14.0 & $0.13(0.01,1.17)$ & & & \\
\hline GetGoal-M-Asia & 107 & 185 & 84 & 188 & 30.3 & $0.59(0.39,0.89)$ & & -- & \\
\hline GetGoal-M & 21 & 40 & 1 & 11 & 14.7 & $0.09(0.01,0.77)$ & & - & \\
\hline GetGoal-S & 100 & 242 & 9 & 123 & 27.9 & $0.11(0.05,0.23)$ & & & \\
\hline GetGoal-P & 8 & 14 & 1 & 7 & 13.2 & $0.13(0.01,1.33)$ & 0.01 & 0.1 & 10 \\
\hline Total (95\% CI) & & 503 & & 338 & 100 & $0.18(0.06,0.57)$ & & s lixisenatide & Favors placebo \\
\hline Total events & 247 & & 96 & & & & & & \\
\hline \multicolumn{10}{|c|}{ Heterogeneity: $\tau^{2}=1.05 ; \chi^{2}=19.31 ; d f=4(P=0.0007) ; I^{2}=79 \%$} \\
\hline \multicolumn{10}{|c|}{ Test for overall effect: $Z=2.94(P=0.003)$} \\
\hline
\end{tabular}

Random-effects model

$C I$ confidence interval, $d f$ degrees of freedom, $H b A l c$ glycated hemoglobin, $O R$ odds ratio

\section{Adverse Reactions}

More patients in the lixisenatide versus placebo group experienced one or more TEAEs [OR 0.60; $95 \%$ CI $(0.45,0.81)$, both fixed and random-effects models].

In total, 12 of $347(3.46 \%)$ patients in the placebo treatment group and 17 of $536(3.17 \%)$ patients in the lixisenatide treatment group experienced at least one serious TEAE $(P=0.49)$. The risk ratios of serious adverse events did not show any statistically significant differences between lixisenatide and placebo group [OR 1.31; 95\% CI $(0.61,2.79)$, both fixed and random-effects models].

\section{Summary of Evidence}

Overall, the evidence is sufficiently robust to confirm that lixisenatide as an adjunct therapy can improve glycemic control of HbA1c in Asian T2DM patients who do not achieve adequate glycemic control with OADs. Also, lixisenatide was superior to placebo in lowering 2-h PPG at the end of the 24-week treatment period. The improvements in glycemic control and the decrease in 2-h PPG were statistically significant and clinically meaningful.

\section{DISCUSSION}

This meta-analysis of more than 800 Asian patients with T2DM shows that a once-daily dose of $20 \mu \mathrm{g}$ of lixisenatide can substantially improve glycemic control in Asian patients who do not achieve an HbA1c target of 7\% with an established regimen of OADs. Both HbA1c and 2-h PPG showed clinically meaningful reductions, with the 2-h PPG reduction being particularly large $(-5.5 \mathrm{mmol} / \mathrm{l})$ after the 24-week treatment course. Both HbA1c and PPG are important components of glycemic control, and the results of our meta-analysis provide evidence that lixisenatide has clinical 


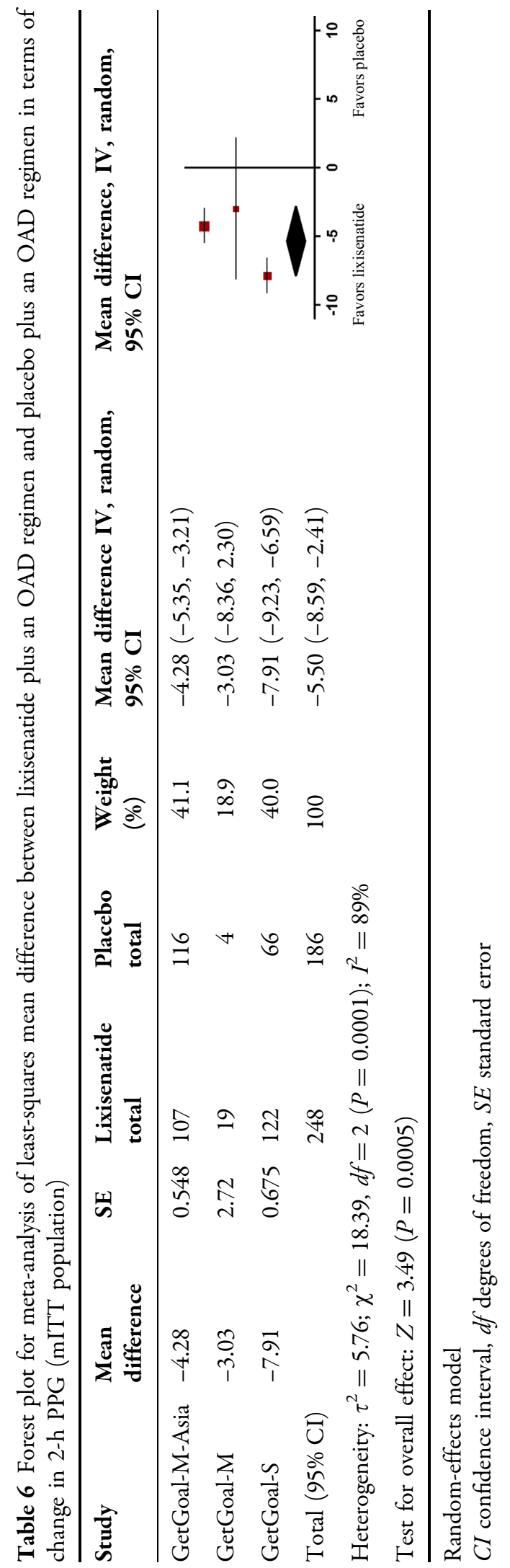

application in Asian patients with T2DM who are inadequately controlled with OADs.

\section{HbA1c Reduction}

Our meta-analysis found that, compared with placebo, lixisenatide, on average, reduced HbA1c by $0.57 \%$ after a 24 -week treatment period. This signifies a clinically meaningful improvement in glycemic control in Asian patients with T2DM who were inadequately controlled with an established OAD regimen.

In the GetGoal-S study, which enrolled 859 patients of mixed ethnic origin (ca. $45 \%$ of them were of Asian origin), the mean baseline HbA1c level was $8.2-8.3 \%$, and the magnitude of the HbA1c reduction was $0.74 \%$. This was more than double that reported in the GetGoal-M-Asia study, which enrolled 391 Asian patients (90\% of them were Chinese) in China, Malaysia, Thailand, and Hong Kong $[17,18]$. The mean baseline HbA1c of patients in that study was relatively low (7.85-7.95\%), and the mean $\mathrm{HbA1c}$ reduction was considerably lower than that in other similar GetGoal studies that enrolled cohorts of mixed ethnic origin. The mean reduction in HbA1c in the present meta-analysis was greater than that reported in the GetGoal-M-Asia study $(-0.36 \%)$. In our meta-analysis, the mean baseline $\mathrm{HbA1c}$ for the lixisenatide and placebo groups was $8.2 \%$ and $8.1 \%$, respectively. Previous studies with GLP-1 receptor agonists showed that higher baseline HbA1c levels correlate with greater reductions in HbA1c [19-23].

The results of our meta-analysis therefore provide consolidated evidence for the value of lixisenatide in achieving glycemic control in Asian patients with T2DM who do not meet target HbA1c values despite an established OAD regimen. 
Table 7 Forest plots for lixisenatide versus placebo in terms of percentage of patients with PPG $\leq 7.8 \mathrm{mmol} / 1$

\begin{tabular}{|c|c|c|c|c|c|c|c|c|}
\hline \multirow[t]{2}{*}{ Study } & \multicolumn{2}{|c|}{ Lixisenatide } & \multicolumn{2}{|c|}{ Placebo } & \multirow{2}{*}{$\begin{array}{l}\text { Weight } \\
(\%)\end{array}$} & \multirow{2}{*}{$\begin{array}{l}\text { Odds ratio } \mathrm{M}-\mathrm{H}, 95 \% \\
\text { CI }\end{array}$} & \multirow{2}{*}{\multicolumn{2}{|c|}{$\begin{array}{l}\text { Odds ratio } \mathrm{M}-\mathrm{H} \text {, random, } \\
95 \% \mathrm{CI}\end{array}$}} \\
\hline & Events & Total & Events & Total & & & & \\
\hline GetGoal-M-Asia & 37 & 109 & 4 & 116 & 63.8 & $0.07(0.02,0.20)$ & 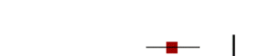 & \\
\hline GetGoal-M & 7 & 19 & 0 & 4 & 16.8 & $0.19(0.01,3.94)$ & $=$ & \\
\hline GetGoal-S & 54 & 122 & 0 & 66 & 19.4 & $0.01(0.00,0.16)$ & & \\
\hline Total (95\% CI) & & 250 & & 186 & 100 & $0.06(0.01,0.22)$ & $\begin{array}{lll}0.001 & 0.1 & 1\end{array}$ & $10 \quad 1000$ \\
\hline Total events & 98 & & 4 & & & & Favors lixisenatide & Favors placebo \\
\hline
\end{tabular}

Heterogeneity: $\tau^{2}=0.46 ; \chi^{2}=2.70, d f=2(P=0.26) ; I^{2}=26 \%$

Test for overall effect: $Z=4.14(P<0.0001)$

Random-effects model

$C I$ confidence interval, $d f$ degrees of freedom, $H b A 1 c$ glycated hemoglobin, $O R$ odds ratio, $P P G$ postprandial glucose

Table 8 Forest plot for lixisenatide versus placebo in terms of percentage of patients with both $\mathrm{HbAlc} \leq 7 \%$ and PPG $\leq 10 \mathrm{mmol} / \mathrm{l}$

\begin{tabular}{|c|c|c|c|c|c|c|c|}
\hline \multirow[t]{2}{*}{ Study } & \multicolumn{2}{|c|}{ Lixisenatide } & \multicolumn{2}{|l|}{ Placebo } & \multirow{2}{*}{$\begin{array}{l}\text { Weight } \\
(\%)\end{array}$} & \multirow{2}{*}{$\begin{array}{l}\text { Odds ratio } \mathrm{M}-\mathrm{H} \text {, } \\
\text { random, } 95 \% \mathrm{CI}\end{array}$} & \multirow{2}{*}{$\begin{array}{l}\text { Odds ratio } \mathrm{M}-\mathrm{H} \text {, random, } \\
95 \% \mathrm{CI}\end{array}$} \\
\hline & Events & Total & Events & $\overline{\text { Total }}$ & & & \\
\hline GetGoal-M-Asia & 39 & 109 & 5 & 116 & 81.7 & $0.08(0.03,0.21)$ & $\rightarrow$ \\
\hline GetGoal-M & 7 & 19 & 0 & 4 & 8.4 & $0.19(0.01,3.94)$ & - \\
\hline GetGoal-S & 41 & 122 & 0 & 66 & 9.9 & $0.01(0.00,0.24)$ & \\
\hline Total (95\% CI) & & 250 & & 186 & 100 & $0.07(0.03,0.18)$ & $\begin{array}{lllll}0.001 & 0.1 & 1 & 10 & 100\end{array}$ \\
\hline Total events & 87 & & 5 & & & & Favors lixisenatide \\
\hline
\end{tabular}

Heterogeneity: $\tau^{2}=0.00 ; \chi^{2}=1.93 ; d f=2(P=0.38) ; I^{2}=0 \%$

Test for overall effect: $Z=5.80(P<0.00001)$

Random-effects model

$C I$ confidence interval, $d f$ degrees of freedom, $H b A 1 c$ glycated hemoglobin, $O R$ odds ratio, $P P G$ postprandial glucose

Antidiabetic drugs that target GLP-1 are promising therapeutic options for Asian T2DM patients and it is postulated that GLP-1 receptor agonists increase glucose uptake, which, in turn, improves peripheral glucose utilization and measures of beta cell function [24, 25].

\section{Two-hour PPG Reduction}

The main antidiabetic effect of lixisenatide as a prandial GLP-1 receptor agonist is to delay gastric emptying, which, in turn, controls PPG excursions [10]. Our meta-analysis reported a large reduction in 2-h PPG $(-5.5 \mathrm{mmol} / \mathrm{l})$ after the 24-week treatment with lixisenatide, which was significantly better than that of the placebo group (weighted, total mean difference $-0.57 \%$; $P=0.0005)$. PPG control is a fundamental component of glycemic control in Asian T2DM because PPG excursions are thought to be more pronounced in Asians than in Westerners with T2DM $[9,26]$. These 
disparities are usually ascribed to differences in eating/dietary habits, whereas physiological variances, such as a faster beta cell degeneration in Asian versus Western T2DM, may also have a role [26]. Consequently, in Asian T2DM, PPG is thought to be a more important contributor to HbA1c than FPG, and prandial GLP-1 receptor agonists are therefore a valuable addition to the treatment arsenal for Asian T2DM.

The reduction in PPG in our meta-analysis is aligned with the results of other studies with prandial GLP-1 agonists.

\section{Body Weight}

To date, GLP-1 receptor agonists have shown some benefits in terms of stable body weight or weight loss in T2DM patients. The effect of T2DM treatment regimens on body weight is an important consideration when selecting treatments for glycemic control because patients are often unwilling to commence, comply with, or intensify treatments that result in weight gain, in particular basal insulin. Treatment intensification with GLP-1 receptor agonists may therefore present a useful alternative to prandial insulin in patients insufficiently controlled with OADs. The results of this meta-analysis show that, at a minimum, body weight was stable over the 24-week treatment period. There was a tendency for weight loss at the end of the study, which might intensify if treatment is continued for a longer period. Nonetheless, another similar study in the GetGoal study programme (GetGoal-S) reported significantly larger reductions in body weight for patients treated with lixisenatide (mean reduction of 0.84 vs. $-0.29 \mathrm{~kg}$ in this meta-analysis). In that study, the mean baseline body weight of patients was approximately $10 \mathrm{~kg}$ greater than that of patients in the meta-analysis.

In general, Asian individuals develop T2DM at a lower BMI than Westerners, and this could explain the generally lower mean body weight of the Asian cohort in our meta-analysis [23]. Nonetheless, in clinical practice, Asian individuals with T2DM do achieve high body weights and high BMIs, and these patients will most likely experience a reduction in body weight when treated with lixisenatide, similar to that of cohorts with a higher mean body weight in other GetGoal studies.

\section{Safety}

Although the incidence of TEAEs was higher in the lixisenatide than in the placebo group, the individual studies that were included in this meta-analysis showed that lixisenatide is generally well tolerated and the adverse events mostly mild to moderate in intensity. GLP-1 receptor agonists have a generally safe profile, and lixisenatide's safety results are consistent with that of other GLP-1 receptor agonists [6].

\section{Limitations}

Observation can alter the behavior of both patients and physicians involved in clinical trials, and this may influence outcome measures, i.e., patients included in this meta-analysis were generally compliant with study protocols, and this may well not reflect real-world circumstances. For instance, in one of the GetGoal studies included in the meta-analysis, a relatively large placebo effect was observed in HbA1c, which is likely due to better patient compliance to diet and lifestyle changes because of more individualized care that is associated with study enrollment [17]. 


\section{CONCLUSIONS}

In the present meta-analysis, lixisenatide as an adjunct therapy was superior to placebo in lowering both HbA1c and 2-h PPG levels of Asian patients with T2DM who were inadequately controlled with an established regimen of OADs. A 24-week treatment period with lixisenatide resulted in a reduction of $0.57 \%$ in mean $\mathrm{HbA1c}$ and a large reduction in 2-h PPG $(-5.5 \mathrm{mmol} / \mathrm{l})$. Patients in the lixisenatide treatment group were significantly more likely than those in the placebo group to achieve HbA1c $\leq 7 \%$ and PPG targets. Lixisenatide is generally well tolerated and the adverse events mostly mild to moderate in intensity. Taken together, lixisenatide as an adjunct therapy has clinical application in Asian patients with T2DM who are inadequately controlled with OADs.

\section{ACKNOWLEDGEMENTS}

Some of the data was published as a poster at the 2016 American Diabetes Association Annual Meeting 76th Scientific Sessions. Sponsorship and article processing charges for this study were funded by Sanofi (China) Investment Co., Ltd., Shanghai, China. Editorial support in the preparation of this publication was provided by Manette Williams (PhD) (Nucleus Shanghai) and paid for by Sanofi. All named authors meet the International Committee of Medical Journal Editors (ICMJE) criteria for authorship for this manuscript, take responsibility for the integrity of the work as a whole, and have given final approval to the version to be published. All authors had full access to all of the data in this study and take complete responsibility for the integrity of the data and accuracy of the data analysis.
Disclosures. H. Shu and J. M. Lu have nothing to disclose. L. Gu and L. Men are full-time employees of Sanofi R\&D.

Compliance with Ethics Guidelines. All procedures in the trials included in this current meta-analysis were in accordance with the responsible committee on human experimentation (institutional and national) and with the Helsinki Declaration of 1964, as revised in 2013. Informed consent was obtained from all patients for being included in the studies. This meta-analysis is based on previously conducted studies, and does not involve any new studies of human or animal subjects performed by any of the authors.

Data Availability. The datasets generated and/or analyzed during the current study are not publicly available because lixisenatide has not been launched in many Asian countries, but data is available from the corresponding author on request.

Open Access. This article is distributed under the terms of the Creative Commons Attribution-NonCommercial 4.0 International License (http://creativecommons.org/licenses/ by-nc/4.0/), which permits any noncommercial use, distribution, and reproduction in any medium, provided you give appropriate credit to the original author(s) and the source, provide a link to the Creative Commons license, and indicate if changes were made.

\section{REFERENCES}

1. International Diabetes Federation. The global burden. http://www.idf.org/diabetesatlas/5e/theglobal-burden. 2012. Accessed 22 Feb 2016.

2. Yoon K, Lee J, Kim J, et al. Epidemic obesity and type 2 diabetes in Asia. Lancet. 2006;368:1681-8. 
3. Chen Y, Liu L, Gu L, Babineaux S, Colclough H, Curtis B. Glycemic control in Chinese patients with type 2 diabetes mellitus receiving oral antihyperglycemic medication-only or insulin-only treatment: a cross-sectional survey. Diabetes Ther. 2015;6:197-211.

4. Ji LN, Zhang PH, Weng JP, et al. Basal insulin treatment in patients with type 2 diabetes uncontrolled on oral antihyperglycemic agents: ORBIT study in China. Diabetes. 2015;64:A235-382.

5. Ji LN, Lu JM, Guo XH, et al. Glycemic control among patients in China with type 2 diabetes mellitus receiving oral drugs or injectables. BMC Public Health. 2013;13:602.

6. Ko GTC, Chan JCN, Woo J, Cockram CS. Prediction of hypertension, diabetes, dyslipidaemia or albuminuria using simple arthropometric indexes in Hong Kong Chinese. Int J Obes. 1999;23:1136-42.

7. Jia WP, Pang C, Chen L, et al. Epidemiological characteristics of diabetes mellitus and impaired glucose regulation in a Chinese adult population: the Shanghai Diabetes Studies, a cross-sectional 3-year follow-up study in Shanghai urban communities. Diabetologia. 2007;50:286-92.

8. Chan JC, So W, Ma RC, et al. The complexity of vascular and non-vascular complications of diabetes: the Hong Kong Diabetes Registry. Curr Cardiovasc Risk Rep. 2011;5:230-9.

9. Ma RCW, Chan JCN. Type 2 diabetes in East Asians: similarities and differences with populations in Europe and the United States. Ann N Y Acad Sci. 2013;1281:64-91.

10. Prasad-Reddy L, Isaacs D. A clinical review of GLP-1 receptor agonists: efficacy and safety in diabetes and beyond. Drugs Context. 2015;4:212-83.

11. Fonseca VA, Alvarado-Ruiz R, Raccah D, et al. Efficacy and safety of the once-daily GLP-1 receptor agonist lixisenatide in monotherapy: a randomized, double-blind, placebo-controlled trial in patients with type 2 diabetes (GetGoal-Mono). Diabetes Care. 2012;35:1225-31.

12. Pinget $\mathrm{M}$, Goldenberg $\mathrm{R}$, Niemoeller $\mathrm{E}$, Muehlen-Bartmer I, Guo H, Aronson R. Efficacy and safety of lixisenatide once daily versus placebo in type 2 diabetes insufficiently controlled on pioglitazone (GetGoal-P). Diabetes Obes Metab. 2013;15:1000-7.

13. Rosenstock J, Raccah D, Korányi L, et al. Efficacy and safety of lixisenatide once daily versus exenatide twice daily in type 2 diabetes inadequately controlled on metformin: a 24-week, randomized, open-label, active-controlled study (GetGoal-X). Diabetes Care. 2013;36:2945-51.

14. Riddle $\mathrm{MC}$, Aronson R, Home $\mathrm{P}$, et al. Adding once-daily lixisenatide for type 2 diabetes inadequately controlled by established basal insulin: a 24-week, randomized, placebo-controlled comparison (GetGoal-L). Diabetes Care. 2013;36:2489-96.

15. Seino Y, Min KW, Niemoeller E, Takami A, EFC10887 GETGOAL-L Asia Study Investigators. Randomized, double-blind, placebo-controlled trial of the once-daily GLP-1 receptor agonist lixisenatide in Asian patients with type 2 diabetes insufficiently controlled on basal insulin with or without a sulfonylurea (GetGoal-L-Asia). Diabetes Obes Metab. 2012;14:910-7.

16. Riddle MC, Forst $\mathrm{T}$, Aronson R, et al. Adding once-daily lixisenatide for type 2 diabetes inadequately controlled with newly initiated and continuously titrated basal insulin glargine: a 24-week, randomized, placebo-controlled study (GetGoal-Duo 1). Diabetes Care. 2013;36:2497-503.

17. Yu Pan C, Han P, Liu X, et al. Lixisenatide treatment improves glycaemic control in Asian patients with type 2 diabetes mellitus inadequately controlled on metformin with or without sulfonylurea: a randomized, double-blind, placebo-controlled, 24-week trial (GetGoal-M-Asia). Diabetes Metab Res Rev. 2014;30(8):726-35.

18. Rosenstock J, Hanefeld M, Shamanna $\mathrm{P}$, et al. Beneficial effects of once-daily lixisenatide on overall and postprandial glycemic levels without significant excess of hypoglycemia in type 2 diabetes inadequately controlled on a sulfonylurea with or without metformin (GetGoal-S). J Diabetes Complicat. 2014;28:386-92.

19. Hanefeld M, Fleischmann H, Landgraf W, Pistrosch F. EARLY study: early basal insulin therapy under real-life conditions in type 2 diabetics. Diabetes Stoffw Herz. 2012;21:91-7.

20. Hanefeld $M$, Bramlage P. Insulin use early in the course of type 2 diabetes mellitus: the ORIGIN trial. Curr Diab Rep. 2013;13:342-9.

21. Imai K, Tsujimoto $\mathrm{T}$, Goto A, et al. Prediction of response to GLP-1 receptor agonist therapy in Japanese patients with type 2 diabetes. Diabetol Metab Syndr. 2014;6:110.

22. Khan M, Ouyang J, Perkins K, Nair S, Joseph F. Determining predictors of early response to exenatide in patients with type 2 diabetes mellitus. J Diabetes Res. 2015;2015:162718. 
23. Esposito K, Mosca C, Brancario C, Chiodini P, Ceriello A, Giugliano D. GLP-1 receptor agonists and HBA1c target of $<7 \%$ in type 2 diabetes: meta-analysis of randomized controlled trials. Curr Med Res Opin. 2011;27:1519-28.

24. Cai X, Han X, Luo Y, Ji L. Efficacy of dipeptidyl-peptidase-4 inhibitors and impact on B-cell function in Asian and Caucasian type 2 diabetes mellitus patients: a meta-analysis. J Diabetes. 2015;7:347-59.
25. Aschner P, Kipnes MS, Lunceford JK, et al. Effect of the dipeptidyl peptidase- 4 inhibitor sitagliptin as mono-therapy on glycemic control in patients with type 2 diabetes. Diabetes Care. 2006;29:2632-7.

26. Yabe D, Seino Y, Fukushima $M$, Seino S. $\beta$ cell dysfunction versus insulin resistance in the pathogenesis of type 2 diabetes in East Asians. Curr Diab Rep. 2015;15:602. 